\title{
Seafloor Sediment Study from South China Sea: Acoustic \& Physical Property Relationship
}

\author{
Zhengyu Hou ${ }^{1,2}$, Changsheng Guo ${ }^{1, *}$, Jingqiang Wang ${ }^{3}$, Wenjing Chen ${ }^{1,2}$, Yongtao Fu ${ }^{1}$ \\ and Tiegang $\mathrm{Li}^{1}$
}

1 Key Laboratory of Marine Geology and Environment, Institute of Oceanology, Chinese Academy of Sciences, NO. 7 Nanhai Road, Shinan District, Qingdao 266071, China;

E-Mails: hansonhzy@foxmail.com (Z.H.); chenwenjing13@mails.ucas.ac.cn (W.C.); ytfu@qdio.ac.cn (Y.F.); tgli@qdio.ac.cn (T.L.)

2 University of Chinese Academy of Sciences, NO. 19 Yuquan Road, Shijingshan District, Beijing 100049, China

3 First Institute of Oceanography, SOA, No. 6 Xianxialing Road, Laoshan District, Qingdao 266061, China; E-Mail: wang_jingqiang@aliyun.com

* Author to whom correspondence should be addressed; E-Mail: guochine@qdio.ac.cn; Tel.: +86-532-8289-8529; Fax: +86-532-8289-8526.

Received: 16 June 2015 / Accepted: 31 August 2015 / Published: 10 September 2015

\begin{abstract}
Seafloor sediments of different geographical areas in the southern South China Sea (continental shelf, continental slope, and Okinawa Trough) were gravity cored at 21 locations. Sound velocities (V) of the samples were measured at $15-\mathrm{cm}$ increments immediately upon retrieval, and porosity, wet bulk density, and mean grain size were measured later in the laboratory. Empirical equations from previous studies were applied to predict $\mathrm{V}$ of sediment samples from the measured physical properties and it was found that the sound velocities derived from the existing equations did not closely match the measured sound velocities. Therefore empirical equations were reconstructed based on the measured data that represent the relationships between physical and acoustic properties of the different geographical area in the study area. Possible explanations for the discrepancies between the measured data and those of previous studies were investigated and found that physical properties, sediment types, geographical area, etc. are important factors that influence sound velocity. The empirical equations of this report should be preferred for prediction of sediment sound velocity for high-frequency acoustic experiments.
\end{abstract}


Keywords: sound velocity; empirical equation; physical properties

\section{Introduction}

The acoustic and physical properties of marine sediments in various geographical areas and sedimentary environments are vital to underwater acoustic environment and explorations of the seafloor, and have also become an important tool for remote sensing the geophysical properties of the oceans. The advent of technology to map the seafloor in great detail at high frequencies has sparked new interest in the acoustic properties (namely, sound velocity and attenuation) of the upper few meters of seafloor sediment [1]. In the past few decades, these have been studied intensively both in deep-sea and shelf regions. In theory, Biot developed Biot theory to estimate the acoustic and physical properties of the uppermost layer in the seafloor [2,3]. Stoll studied the propagation of acoustic waves in marine sediment and adapted the Biot model to describe acoustic propagation in unconsolidated marine sediments [4]. Hamilton published numerous papers dealing with the acoustic characteristics of marines sediments from various environments worldwide [5-7]. These properties include compressional and shear wave velocities, attenuation, porosity, water content, sand-silt-clay content, wet bulk density, and other physical properties. Hamilton and Bachman [8] used laboratory measurements of sediment properties in cores from the Bering Sea, North Sea, Mediterranean Sea, equatorial Pacific, and other areas to establish empirical equations for sound velocity in seafloor sediments. Orsi and Dunn [9] showed a correlation between sound velocity and physical properties of fine-grained abyssal sediments from the Brazil Basin. Brandes et al. [10] provided a Geoacoustic characterization of calcareous seabed areas in the Florida Keys. Lambert et al. [11] studied the acoustic response of shallow-water marine sediments at six sites within the Ship Island Test Bed off Gulfport, Mississippi. And a comparably small number of studies dealing with bottom sediment physical properties are available from the international literature (e.g., [12-14]). The most recent and comprehensive collection of regressions for various world regions is contained in Jackson and Richardson [15].

The geoacoustic study started relatively rather late in China. Lu et al. [16,17] conducted experiments in the southeastern coastal areas of China (including the South China Sea, Taiwan Strait, and continental shelf of the East China Sea) and established empirical equations for the sound velocity of seafloor sediments in these study areas. Kan et al. [18] and Liu et al. [19] used an in situ system to study sediment acoustics in the Yellow Sea, and established empirical equations for the relationships between sediment characteristics and acoustic properties there.

One of the most useful acoustic properties for seafloor sediment characterization is compressional wave velocity (hereinafter called "sound velocity" or V). Sound velocity can be used for seafloor mapping, geotechnical seafloor studies, and various other marine substrate studies.

In this work, we tested whether the established empirical equations mentioned above could be applied equally well to sound velocity data we obtained from various geographical areas (continental shelf, continental slope, and Okinawa trough) in the South China Sea. We collected 21 sediment cores in various environments of the southern South China Sea, which we analyzed aboard ship and again in the laboratory. We present our results and conclusions regarding the relationships of sound velocity to 
sediment physical properties in different geographical areas, and new empirical equations, which deviate from previously established equations.

\section{Study Area}

The southern South China Sea presents a ladder bottom topography comprising three steps with gradually increasing depth from south to north (Figure 1). The first level is the continental shelf, which comprises $17.2 \%$ of the study area and has water depths of less than $150 \mathrm{~m}$. The second level is the continental slope, accounting for $77.6 \%$ of the study area, with water depths of $150-3800 \mathrm{~m}$. The third level is the Okinawa Trough, a deep-sea basin comprising 5.2\% of the study area, with water depths of more than $3800 \mathrm{~m}$. Seafloor sediments in the study area are fine-grained, mainly silty clays with abundant foraminifera and shell fragments. The varying sedimentary environments of these three distinct tiers lead to variability in their physical properties, which affects sound velocities of the sediments.

At present, the research of the sediment acoustics is mainly concentrated in the Yellow Sea, the East China Sea shelf, and the continental shelf of the South China Sea. However, the acoustic studies of the sediments in the South China Sea are relatively less and there is lack of comparisons with empirical equations. And furthermore the South China Sea has unique significance in acoustic research for unique morphology, geographic location, and complicated sedimentary environment.

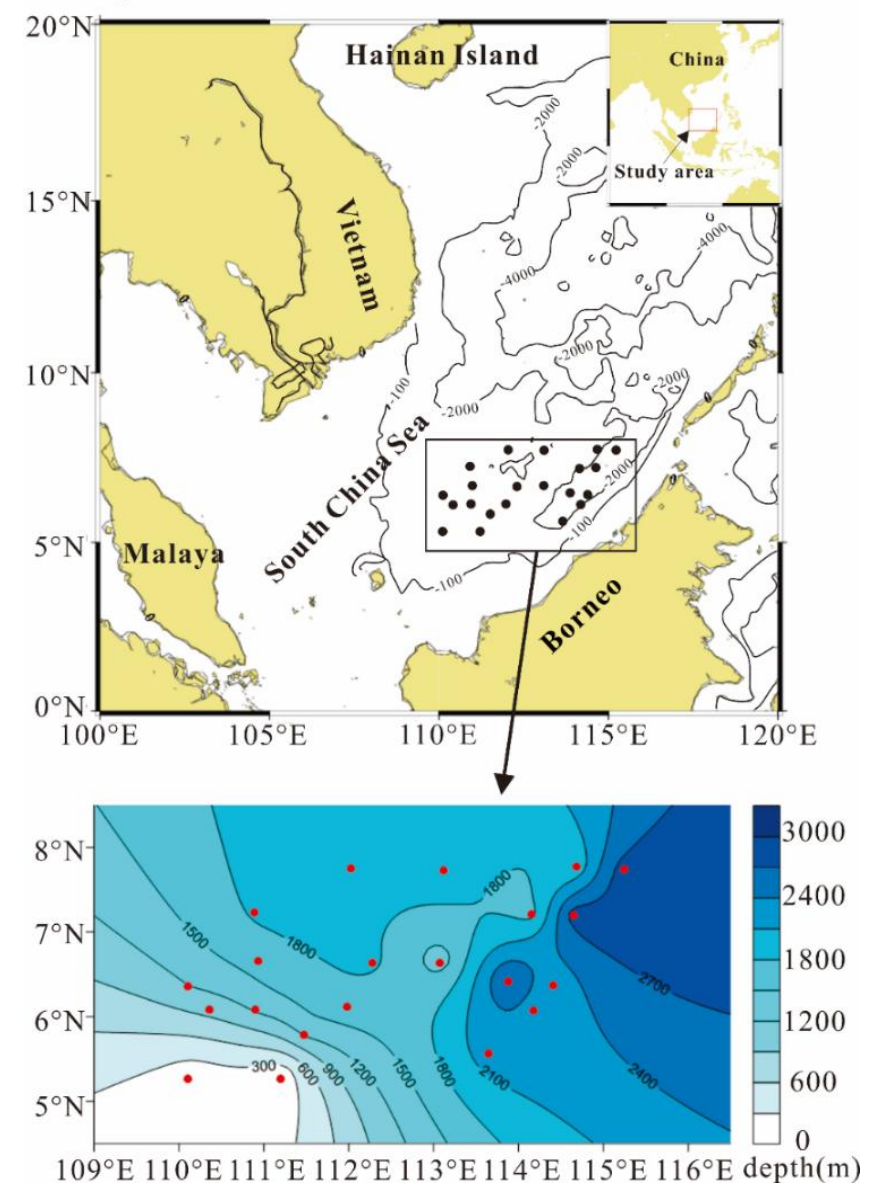

Figure 1. Map of bathymetry and the coring stations. 


\section{Methods}

We have collected seafloor sediment samples from 21 sites in the southern South China Sea (Figure 1). Two samples were from the continental shelf (water depths less than $150 \mathrm{~m}$ ), 13 were on the continental slope (water depths 1053-2028 m), and six were in the Okinawa Trough (water depths 2207-2843 m).

All samples were collected with a gravity corer from the upper $100 \mathrm{~cm}$ of the seafloor. Although gravity coring disturbs the surface sediment to a certain extent, we reduced the disturbance by inserting a polyethylene core liner in the gravity corer barrel. Upon retrieval of the corer, we removed the core liner and the cylindrical sample it contained and immediately measured sound velocity of the samples.

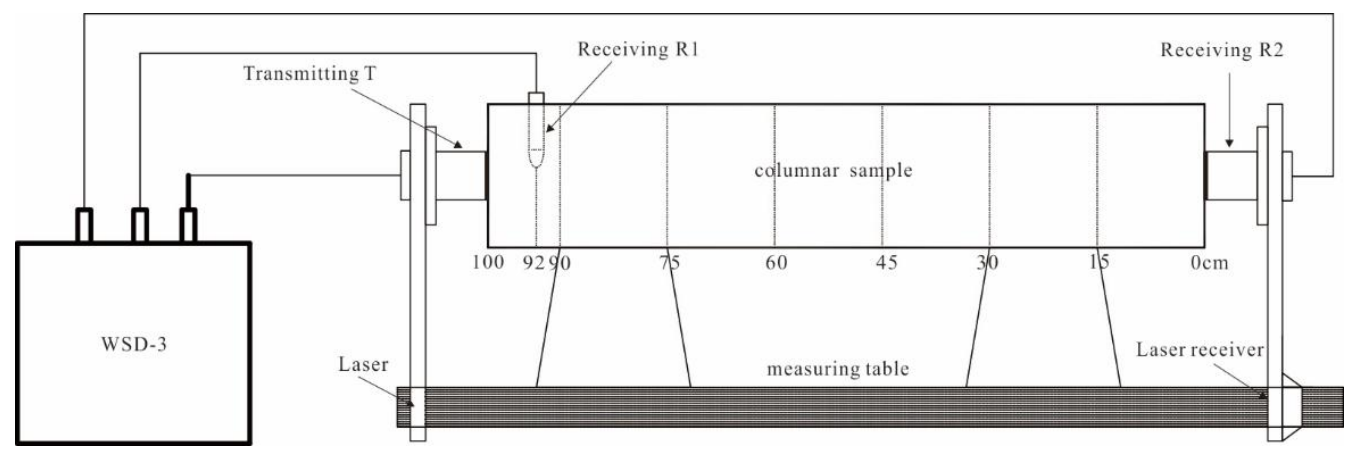

Figure 2. Coaxial differential distance measurement method.

Sound velocity (V) was measured on the deck of the research vessel using a portable WSD-3 digital sonic instrument and the coaxial differential distance measurement method (Figure 2). In order to improve the measurement accuracy, we have designed a measuring platform (Figure 2). Differing from the traditional distance measurement method, this measuring platform adopts the optical measuring method, which can reduce length measurement errors and thus improves sound velocity calculation accuracy. During the measurement, the laser is fixed, the laser receiver is moving with the measuring rod, and thus, according to the principle of the pulse laser range system, the sediment sample can be accurately measured.

The measurement parameters were as follows: the cylindrical sediment sample initial length was 100 $\mathrm{cm}$; the sediment measurement interval was $15 \mathrm{~cm}$; the frequency of pulse signal was $100 \mathrm{kHz}$; the sound wave sampling length was 1024 points; and the sound wave sampling interval was $1 \mu \mathrm{s}$.

Each core was prepared for acoustic testing using the following steps (Figure 2).

(1) The intact cylindrical sample within the polyethylene core liner was placed on the measuring table immediately upon retrieval.

(2) The WSD-3 transducers were connected to the sediment core.

(a) The receiving transducer R1 was inserted into the sediment core at the position of $92 \mathrm{~cm}$.

(b) The transmitting transducer $\mathrm{T}$ was pressed firmly against the sediment core at the bottom of the core (at the position of $100 \mathrm{~cm}$ ).

(c) The receiving transducer R2 was pressed firmly against the sediment core at the bottom of the core (at the position of $0 \mathrm{~cm}$ ). 
Acoustic testing began with the transmitting transducer $\mathrm{T}$ sending acoustic signals. The receiving transducers R1 (at $92 \mathrm{~cm}$ ) and R2 (at $0 \mathrm{~cm}$ ) received the signals, and these were recorded by the WSD-3 system.

When the measurement was completed, the lower $15-\mathrm{cm}$ section of the cylindrical sediment sample was removed. Then the receiving transducer R2 was pressed firmly against the new base of the core, at $15 \mathrm{~cm}$, and the sample was measured as described above. This process was repeated at $15-\mathrm{cm}$ increments until the cylindrical sample was only $10 \mathrm{~cm}$ long.

For each core, seven signals (at 0, 15, 30, 45, 60, 75, and $90 \mathrm{~cm}$; Figure 3) received by transducer R2 were recorded. The results were normalized to obtain scaled amplitude values between 1 and -1 . We used the coaxial differential distance method in Equation (1) to calculate sound velocity. In Equation (1), the signal travel times (by the first arrival) at the seven sample intervals are $\mathrm{t}_{1}, \mathrm{t}_{2}, \mathrm{t}_{3}, \mathrm{t}_{4}, \mathrm{t}_{5}, \mathrm{t}_{6}$, and $\mathrm{t}_{7}$. The time difference between two adjacent signals is $t_{i}-t_{i+1}$, and the length (L) between the two signals is $15 \mathrm{~cm}$. The sound velocity $(\mathrm{V})$ is obtained as follows:

$$
V_{i}=\frac{L}{t_{i}-t_{i+1}}, i=1,2, \ldots, 6
$$

After the acoustic properties were measured aboard the ship, the seven sediment core sections were put in separate pre-weighed $25-\mathrm{ml}$ beakers, sealed with plastic wrap, and awaited for transport to the laboratory for further testing.

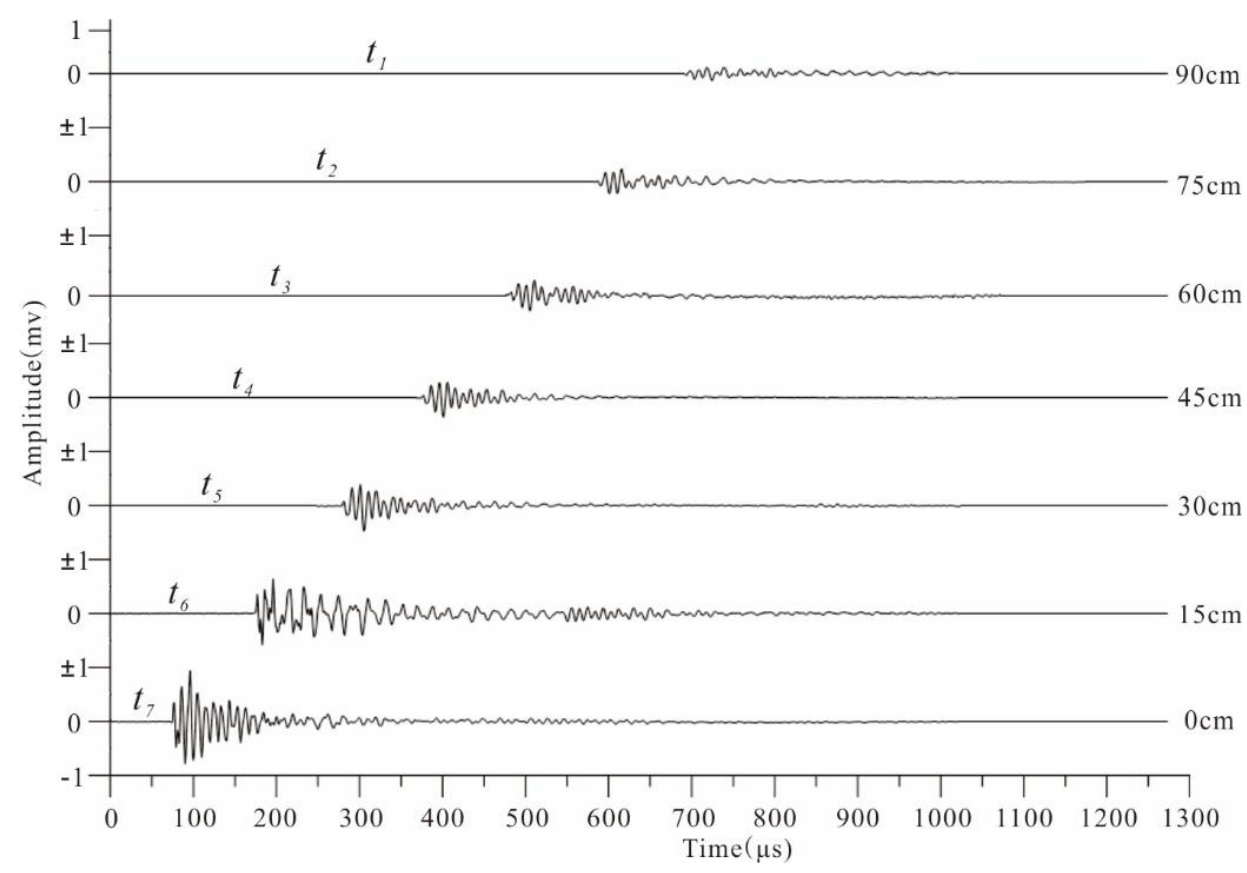

Figure 3. The waveforms received by transducer R2 from one columnar sample.

In the laboratory, physical properties including the mean grain size, wet bulk density, and porosity were determined for each subsample. The mean grain size was measured at the Key Laboratory of Marine Geology and Environment, Institute of Oceanology, Chinese Academy of Sciences (IOCAS) using a Cilas 940L particle size analyzer (particle size measurement range of -1 to $11.7 \phi$ ). Here we report the mean grain size in the form of $\phi$, where $\phi=-\log _{2}(\mathrm{M} / \mathrm{M} 0)$ and $\mathrm{M}$ is the grain diameter in $\mathrm{mm}$, 
$\mathrm{M} 0=1 \mathrm{~mm}$. Wet bulk density was determined by the cutting ring method. Porosity was calculated using the pycnometer method.

\section{Results and Discussion}

The correlations between sound velocity of the samples and the measured physical properties of the sediments are presented in plots to illustrate the ranges and scatter of the data. Porosity ranges from $24 \%$ to $86 \%$, with a coefficient of variation (CV) of $20.44 \%$. The wet bulk density is $1.01-1.83 \mathrm{~g} / \mathrm{cm}^{3}$, with $\mathrm{CV}=12.23 \%$. There may be little measurement errors in the wet weight of sediments which was measured on deck, so the wet density has a minimum value of $1.00 \mathrm{~g} / \mathrm{cm}^{3}$. These errors may come from the gas, water loss, and the scale. The mean grain size is 3.8-8.6 $\phi$, with $\mathrm{CV}=15.97 \%$ and the sorting coefficient $(\sigma)$ of the grain size is 1.46 . The empirical equations for the illustrated data are presented in the text.

\subsection{Porosity}

In a gas-free sediment, the volume of the voids (or pore spaces between the mineral grains) occupied by water are expressed as porosity (volume of voids/total volume). Porosity has a significant effect on acoustic travel time of the sediment; therefore, accurate porosity data are very important for estimating sound velocity. We divided the different geographical areas (continental shelf, continental slope, and Okinawa Trough) of the study area into two zones based on water depth. The continental shelf is the shallow zone (S), while the deep zone (D) contains the continental slope and the Okinawa Trough.

We used the least squares method to study the relationship between sound velocity and porosity for our samples in the two zones ( $\mathrm{S}$ and D) and in the entire study area (T) (Figure 4) and established sets of empirical equations based on the data from our 21 samples. Seafloor sediments collected for this study in the southern South China Sea are mainly silty clays with porosities ranging from $24 \%$ to $86 \%$. The velocity ranges from $1485-1595 \mathrm{~m} / \mathrm{s}$ in zone $\mathrm{S}$ and $1412-1543 \mathrm{~m} / \mathrm{s}$ in zone D. Sound velocity as a function of porosity can be described by a quadratic equation. Generally, with increasing porosity, $\mathrm{V}$ decreases until the porosity reaches a certain value $\mathrm{N}$ (critical porosity, Table 1), after which $\mathrm{V}$ increases as porosity increases.

The relationship between $\mathrm{V}$ and porosity has received much attention in past studies. Porosity is an important variable in the estimation of sediment sound velocity because of its relatively small correlation error [20]. It is also easy to obtain. Hamilton and Bachman [8], Anderson [21], and Lu et al. [16] derived empirical equations for the relationship between $\mathrm{V}$ and porosity based on large numbers of seafloor sediment samples. The curve for the equation derived in this study, based on data from the entire study area, was compared with the curves for equations (H), (A), and (L) (Figure 4). The N values of the results of these four empirical equations are different (Table 1) although four curves (H, A, L, and T) show similar trends. Our empirical equation ( $\mathrm{T}$ ) covaries best with Hamilton's Geoacoustic model [5], while the Hamilton and Bachman [8] equation $(\mathrm{H})$ yields a curve with V slightly higher than the measured values of our samples for a given porosity. Equation (A) also yields $\mathrm{V}$ slightly higher than our measured values. For porosities of about $48 \%-76 \%$, equation (L) is in good agreement with our measurement. The equations used in Figure 4 are listed as follows: 
Equation $(\mathrm{H})$ : Hamilton \& Bachman $(\mathrm{H}), \mathrm{V}=2502.0-23.45 \mathrm{n}+0.14 \mathrm{n}^{2}$

Equation (AH): Hamilton \& Bachman abyssal hill (AH), V = 1410.6 - 1.177n

Equation (A): Anderson (A), V = 2506 - 27.58n+0.1868n ${ }^{2}$

Equation (L): Lu et al. (L), $V=2470.7-32.2 n+0.25 n^{2}$

Equation (T): The entire study area $(T), V=1841-11.62 n+0.08493 n^{2}$

Equation (S): The shallow zone (S), V = $1795-10.46 n+0.08907 n^{2}$

Equation (D): The deep zone (D), V = $1864-12.45 n+0.09182 n^{2}$

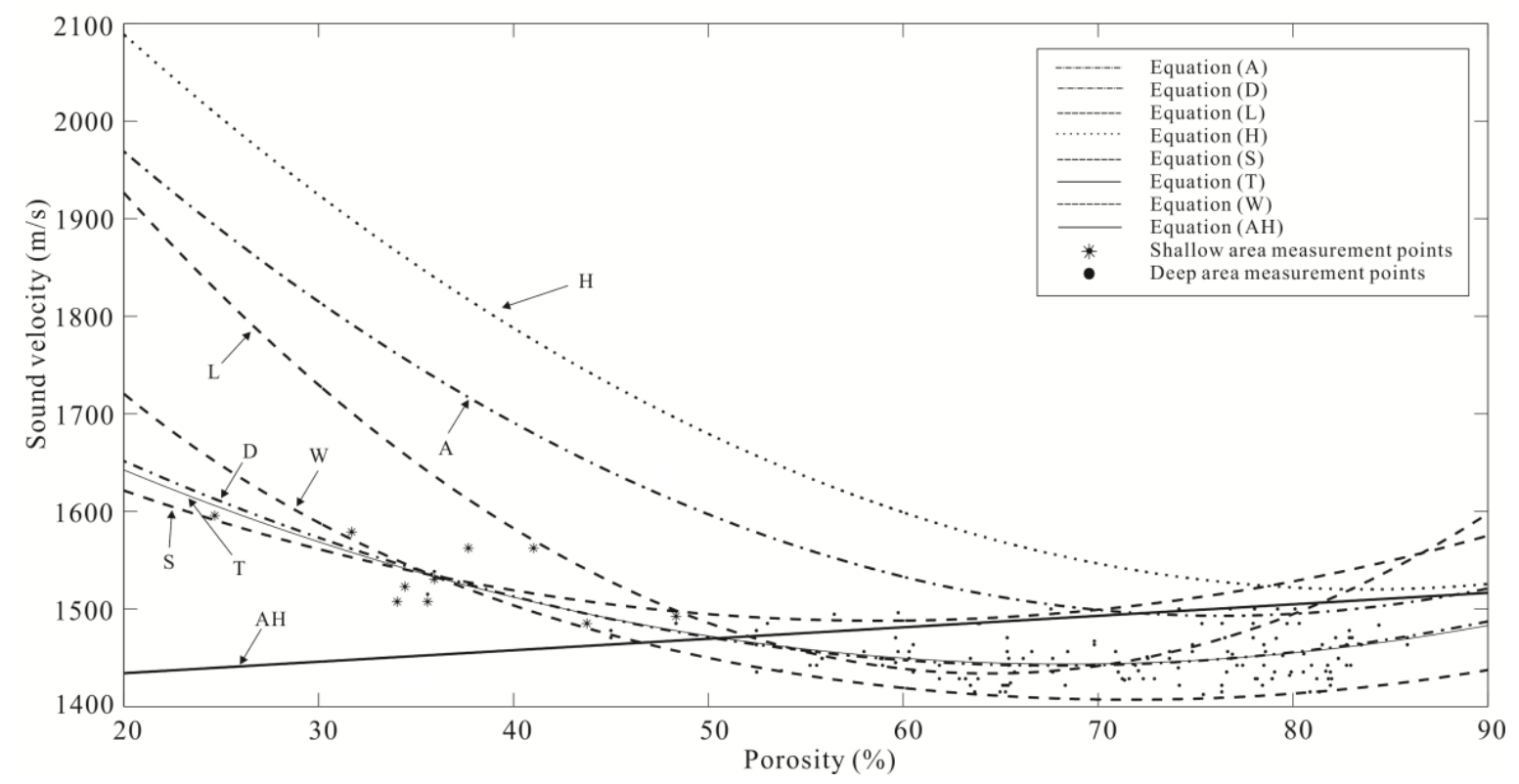

Figure 4. Porosity versus sound velocity; $\mathrm{H}$ is Hamilton and Bachman [8] equation, $\mathrm{AH}$ is Hamilton and Bachman [8] abyssal hill equation; A is Anderson [21] equation; L is Lu et al. [16] equation; $\mathrm{T}$ is the equation established in the paper; $\mathrm{S}$ is the shallow area equation; $\mathrm{D}$ is the deep area equation; the star $\left(^{*}\right)$ point indicates shallow area measurement points and the $\operatorname{dot}(\bullet)$ point indicates deep area measurement points.

Table 1. The empirical equations of $\mathrm{N}$ values and corresponding sound velocity.

\begin{tabular}{ccc}
\hline Equation & $\mathbf{N}(\%)$ & Velocity $(\mathbf{m} / \mathbf{s})$ \\
\hline Anderson [21] & 73.82 & 1487.99 \\
Hamilton \& Bachman [8] & 83.75 & 1520.03 \\
Lu et al. [16] & 64.40 & 1433.86 \\
The entire study area (T) & 68.41 & 1443.54 \\
\hline
\end{tabular}

\subsection{Wet Bulk Density}

Sediment wet bulk density is defined as the sediment mass per unit volume in the raw state. Wet bulk density depends on particle density, porosity volume, and pore water composition. The velocity-wet bulk density relationship for marine sediments is a function of mineral composition, sub-bottom depth, and depositional and diagenetic history. $\mathrm{V}$ in marine sediments generally increases with increasing wet bulk density (Figure 5). Generally, V and wet bulk density are strongly correlated [1]. As shown in the Figure 5, when the measured density of our samples is less than $1.17 \mathrm{~g} / \mathrm{cm}^{3}, \mathrm{~V}$ increases slightly or remains unchanged 
as wet bulk density decreases. When wet bulk density is greater than $1.17 \mathrm{~g} / \mathrm{cm}^{3}$, velocity increases with increasing wet bulk density. The inflection point predicted by the equation of Hamilton and Bachman [8] is $1.4 \mathrm{~g} / \mathrm{cm}^{3}$. For the same density, Hamilton's equation predicts a V higher than our measured V (Figure 5), just as it predicts higher values of $\mathrm{V}$ for a given measured porosity (Figure 4). The equations used in Figure 5 are listed as follows:

Equation $(\mathrm{H})$ : Hamilton \& Bachman $(\mathrm{H}), \mathrm{V}=2330.4-1257.0 \rho+487.7 \rho^{2}$

Equation $(\mathrm{T})$ : The entire study area $(\mathrm{T}), \mathrm{V}=2117-1151 \rho+492 \rho^{2}$

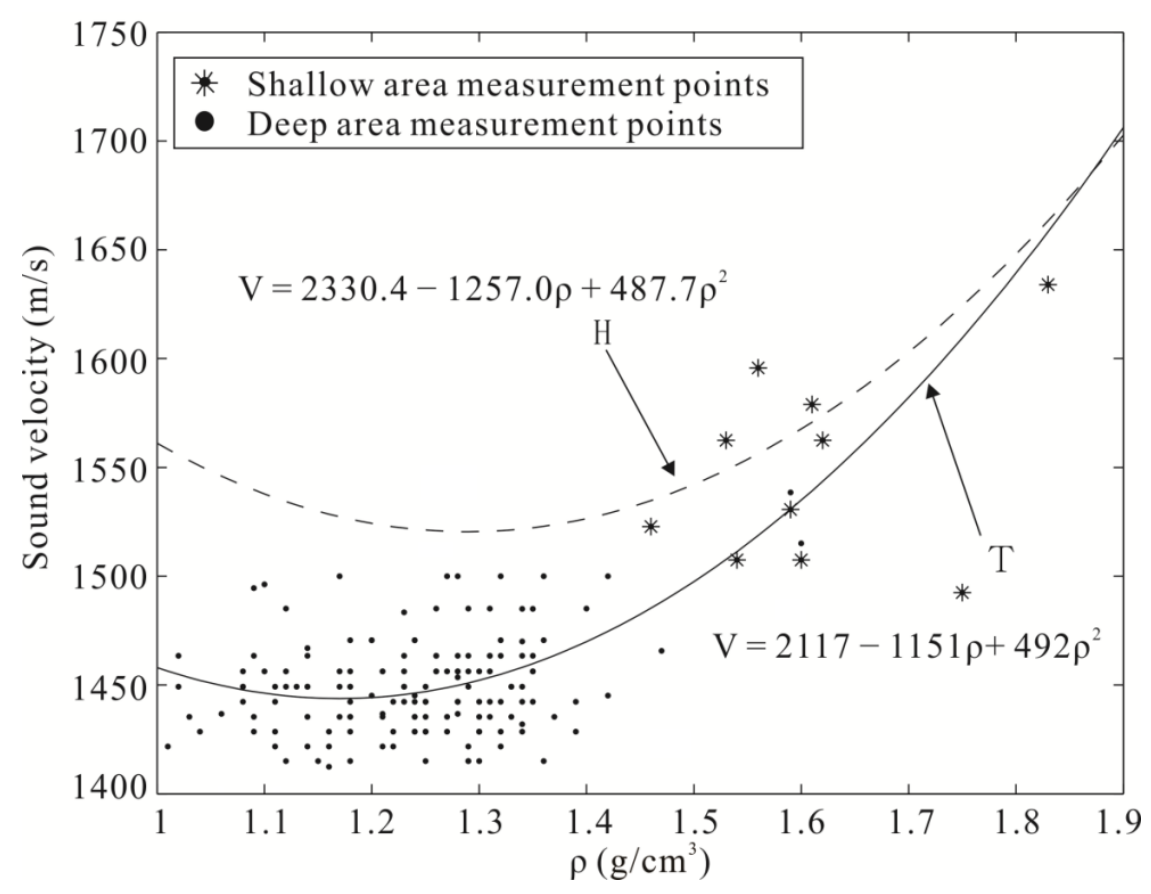

Figure 5. Wet bulk densities versus sound velocity.

According to the elastic wave theory [15], marine sediment can be considered as mineral particles in a framework containing pores filled with seawater. The acoustic properties of sediment pore fluid and the mineral framework are significantly different; the porosity of fluid-filled sediment is related to density and density is a fundamental part of the equation for $\mathrm{V}$ :

$$
V=\sqrt{\frac{k_{b}+\frac{4}{3} G}{\rho}}
$$

$\mathrm{Kb}(\mathrm{Pa})$ is the compressional bulk modulus and $\mathrm{G}(\mathrm{Pa})$ the dynamic shear modulus of sediment [15]. Wet bulk density can be affected by mineralogy, compaction, consolidation of sediment, and water content [8]. Generally, seafloor sediment is composed of mineral particles and fluid filling the voids among the particles. The sediment density $(\rho)$ can be calculated using the mineral particle density $(\rho g)$, fluid density ( $\rho w)$, and porosity $(\mathrm{n})$. The equation is given as:

$$
\rho=n \rho_{w}+(1-n) \rho_{g}
$$

The variations in mineral particle density $(\rho g)$ and fluid density $(\rho f)$ are small and the critical factor affecting sediment density $(\rho)$ is porosity (n). Figure 5 shows that the densities of sediment in the shallow are larger than that of the deep area. Because the density is related with median particle diameter: the 
density increases with the increase of median particle diameter [22]. According to the sedimentary differentiation, the coarse-grained sediment or heavy particles settle down at first, in the shallow area, and fine-grained sediment or light ones will deposit in the distance, in the deep area.

\subsection{Mean Grain Size}

The relationships between grain size and V are especially important, for grain size can be measured in sediment and unaffected by water loss. Density and velocity measurements are unable to be reliably measured due to water loss. However, accurate grain size composition data are abundant in the geologic literature, and can be used as indices to some acoustic properties [8]. The mean grain size of our samples ranges from 3.8 to $8.5 \phi$, and $\mathrm{V}$ increases with increasing mean grain size (Figure 6), which agrees with previous studies $[1,7,8,23]$. Our regression equation is also a quadratic polynomial equation and follows the general trend of the Hamilton Geoacoustic model [5]. The equations used in Figure 6 are listed as follows:

Equation (H): Hamilton \& Bachman (H), V = 1952.5-86.26 Mz + 4.14 Mz ${ }^{2}$

Equation (T): The entire study area $(\mathrm{T}), \mathrm{V}=2210-216.8 \mathrm{Mz}+15.07 \mathrm{Mz}^{2}$

Neto et al. considered sediment grain size to be the most important factor in the variability of seafloor acoustic data [24]. The grain-size parameters of a given sample remain unchanged whether it is on the seabed or in the laboratory. In this study we use the mean grain size as a representative of sediment texture because the mean grain size is a better index for sediment physical properties than median particle diameter [25]. The shallow area (continental shelf) with a coarser mean grain size range typically has comparatively higher sand and silt contents as well as lower clay content than the deep (slope and trough) areas (see Table 2).

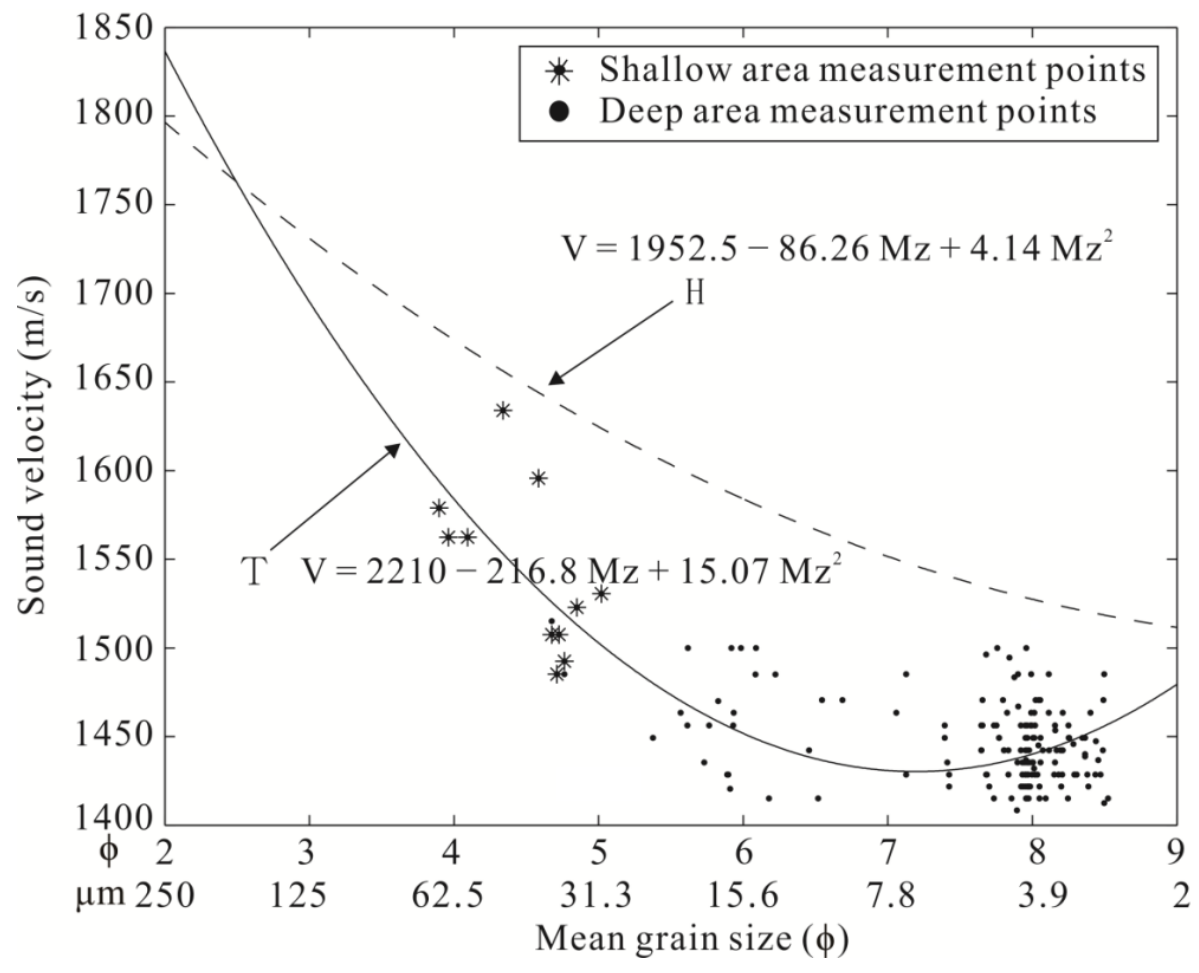

Figure 6. Mean grain sizes versus sound velocity. 
Table 2. Sand-silt-clay ratios and water depth in different geographical areas.

\begin{tabular}{|c|c|c|c|c|c|c|c|}
\hline \multicolumn{2}{|c|}{ Geographical Area } & Type & Water Depth (m) & Velocity $(\mathrm{m} / \mathrm{s})$ & Sand $(\%)$ & Silt (\%) & Clay $(\%)$ \\
\hline \multirow{3}{*}{$\begin{array}{c}\text { Shallow } \\
\text { areas }\end{array}$} & \multirow{3}{*}{$\begin{array}{l}\text { Continental } \\
\text { shelf }\end{array}$} & Mean & 142 & 1533.47 & 34.02 & 55.37 & 10.61 \\
\hline & & Max & 148 & 1595.74 & 53.04 & 70.73 & 12.06 \\
\hline & & Min & 136 & 1485.15 & 18.53 & 38.16 & 6.86 \\
\hline \multirow{6}{*}{$\begin{array}{l}\text { Deep } \\
\text { areas }\end{array}$} & \multirow{3}{*}{$\begin{array}{l}\text { Continental } \\
\text { slope }\end{array}$} & Mean & 1605 & 1447.14 & 0.20 & 54.39 & 45.41 \\
\hline & & $\operatorname{Max}$ & 2028 & 1543.21 & 3.96 & 86.18 & 57.63 \\
\hline & & Min & 1053 & 1415.10 & 0.00 & 42.37 & 12.53 \\
\hline & \multirow{3}{*}{ Trough } & Mean & 2521 & 1448.83 & 0.15 & 51.98 & 47.87 \\
\hline & & $\operatorname{Max}$ & 2843 & 1500.00 & 1.12 & 88.86 & 64.92 \\
\hline & & Min & 2207 & 1412.43 & 0.00 & 35.08 & 10.02 \\
\hline
\end{tabular}

\subsection{Clay Content}

The clay content in seafloor sediment and mean grain size are important variables for determining sediment acoustic properties [25]. Clay content refers to the percentage of sediment particle diameter less than $0.04 \mathrm{~mm}$ in the sediment. Clay content affects $\mathrm{V}$ through its influence on porosity and wet bulk density [8]. Seafloor sediment in the study area is mainly fine-grained silty clay and clayey silt (Table 2). The sound velocity-clay content relationship is generally a linear relationship: V decreases with increasing clay content (Figure 7). The regression line of our equation runs almost parallel to that of Hamilton's Geoacoustic model [5], with a lower velocity of 50-80 m/s. The equations used in Figure 7 are listed as follows:

Equation (H): Hamilton \& Bachman (H), V = 1549.4 - 0.66C

Equation $(\mathrm{T})$ : The entire study area $(\mathrm{T}), \mathrm{V}=1537-1.819 \mathrm{C}$

Compared to the deep area, the shallow area (continental shelf) has a lower clay content that varies within a smaller range (about 6\%-13\%), and greater variation in V (range of about $150 \mathrm{~m} / \mathrm{s}$ ). The deep areas (continental slope and deep trough) have a higher clay content that varies within a wider range (about 10\%-65\%), and a smaller variability in $\mathrm{V}$ (range of about $90 \mathrm{~m} / \mathrm{s}$ ) (Figure 7). The difference in clay content is caused by the long-range transport function of the seawater. Fine-grained particles are transported in suspension and dispersed to the deep area while coarse sand tends to remain in the shallow area. When clay content is low ( $<13 \%$ in Figure 7$)$, V exhibits considerable variation, and is largely unaffected by clay content because of the stronger influence of other physical properties. When clay content is greater than $13 \%, \mathrm{~V}$ decreases with increasing clay content. The increasing clay content results in increasing porosity, contributing to the velocity decrease.

\subsection{Sound Velocity}

The measured data covaries well with the Hamilton Geoacoustic model [5], however, the sound velocity values calculated from the empirical equations of Hamilton and Bachman [8] (Figures 4-6) are slightly higher than our measured values. Most of the sound velocity measurements that Hamilton and Bachman [8] based their regressions on were laboratory measurements of transverse (across the diameter of the core) $200-\mathrm{kHz}$ signals using a pulse technique and a Hamilton frame. In this paper, the sound 
velocity measurements are based on 100-kHz signals transmitted axially through the core using a newly designed optical measuring platform. It seems unlikely that differences in the measurement techniques of the physical properties could account for the differences in the regression results. Other possible causes include differences in acoustic measurement techniques, disturbance of sediments measured with the Hamilton frame, or actual differences in the sediment types and geographical areas. The sand-siltclay ratios of our samples are presented as Shepard ternary diagrams (Figure 8). The concentrations of sand, silty sand, sandy silt, and sand silt clay particles in the Hamilton-Bachman data set (see Hamilton and Bachman, 1982, Figure 1) are higher than those in the sediments analyzed in this study. Moreover, our data are mainly for silty clay and clayey silt. On a micro level, this can result in differences in the sound velocity calculation results.

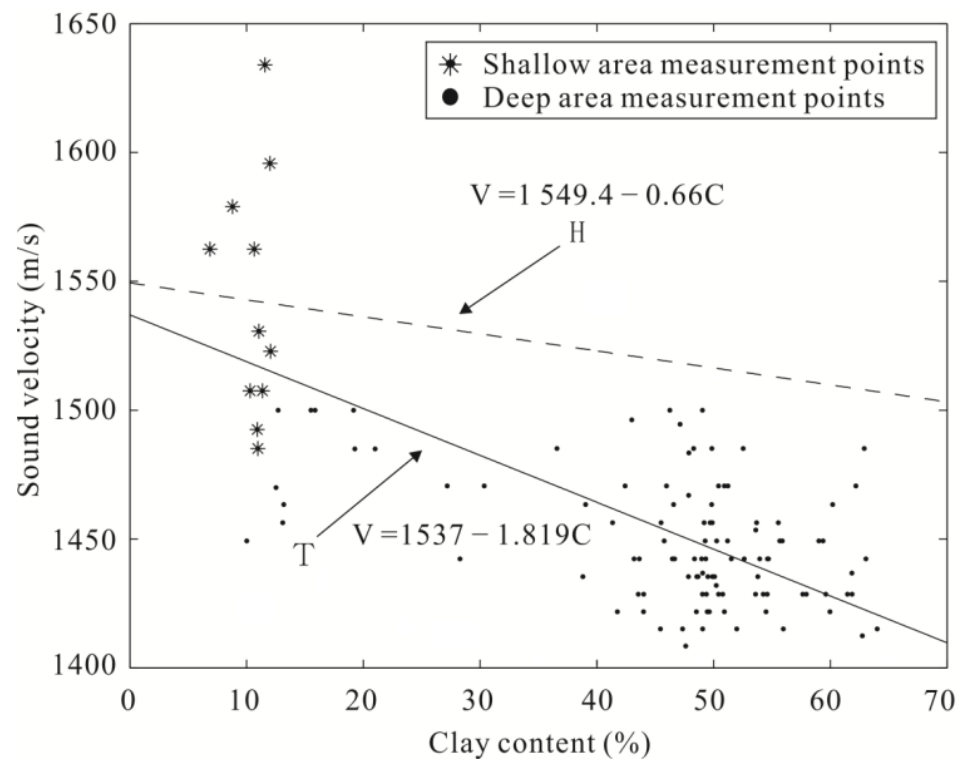

Figure 7. Clay content versus sound velocity.

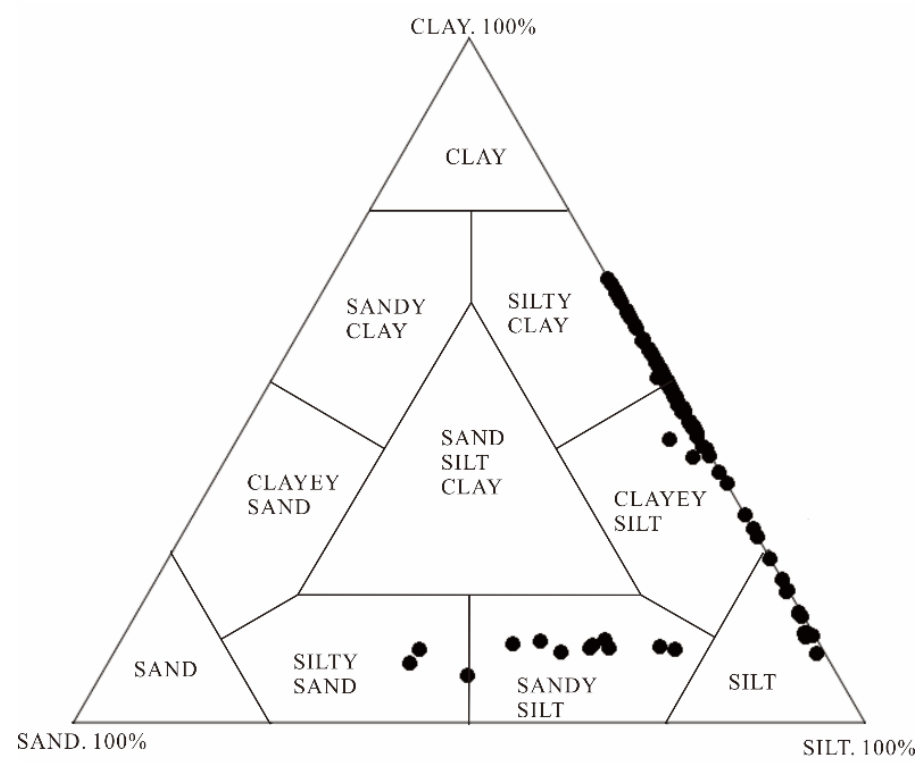

Figure 8. The ratios of sand, silt, and clay for sediment in the acoustic-physical property regression of this paper. 
The environmental conditions of the geographical areas [26] and sediment types are important factors that influence sound velocity, and empirical sound velocity equations in different geographical area have different accuracy. We derived the shallow zone equation (S) and deep zone equation (D) based on the different geographical areas (Figure 4); both equations are in good agreement with the Hamilton frame [5]. However, for porosity ranges of approximately $20 \%-45 \%$, equation $(\mathrm{S})$ is better fitting to the measured sound velocities compared with equation (D), while for porosities $>45 \%$, (D) is more appropriate for the measured sound velocities. In Figure 4, when the porosity is greater than approximately 50\%, our measured data shows an almost perfect match to the Hamilton and Bachman [8] abyssal hill equation (AH) with a lower velocity of about $30-50 \mathrm{~m} / \mathrm{s}$. The sound velocities in the different geographical areas are different. The $\mathrm{V}$ used is the average for each $100-\mathrm{cm}$ core. The average $\mathrm{V}$ in the continental shelf area is above $1480 \mathrm{~m} / \mathrm{s}$ while the continental slope and Nansha Trough are low-velocity zones, with an average $\mathrm{V}$ below $1480 \mathrm{~m} / \mathrm{s}$ and values below $1450 \mathrm{~m} / \mathrm{s}$ in most of the area. The slope and trough sediments show lower velocities than the North Pacific sediments in the geoacoustic model of Hamilton [5]. The sediment type in the shallow area is mainly sand-silt with sand content of 18\%-53\% (Table 2), and the deep area is mainly silty clay sediments. The different sediment type produces a regular change trend of the main physical properties from the shallow area to the deep area (Figures 4-7). The different geographical areas and sediment types lead to the differences of physical properties, and the differences in $\mathrm{V}$ in the different geographical units. The sediment particle size tapers from the shallow area to the deep area; coarse-grained sediments remain in the shallow area while the fine particles are carried to the deep zone (Table 2). Sediments in the deep area are characterized by fine grain size, high porosity, low density and low sound velocity. Compared with the sediments of the deep area, the sediments of the shallow area are characterized by coarser mean grain size (Mz), lower porosity, higher wet bulk density, and higher sound velocity (Figures 4-7). Sound velocity in sediment is also closely related to its porosity and therefore its density [26]. At the seafloor, high porosity/low density sediments, such as mud, have sound velocity only slightly less (up to 3\%) than that of the overlying water; low porosity/high density sediments, such as hard sands, have velocity $10 \%-20 \%$ greater than that of the overlying water [26]. These higher velocities are due to the presence of rigidity and frame bulk modulus in the mineral structure of the sediments [6]. The low sound velocity effect in high porosity mud or silty clays is the result of a balance between water and mineral compressibility (or bulk moduli) and densities, plus low rigidity and low mineral frame bulk moduli [6].

Chen et al. [27] used sediments in the southern South China Sea to measure the sound velocity and inverted sound velocity. Their laboratory sound velocity measurements were 1426-1679 m/s, and the inverted sound velocity result was $1477-1681 \mathrm{~m} / \mathrm{s}$. This is consistent with the results of our measurements. We also calculated sound velocities using Buckingham's theory [28,29] and compared them with our measured data. The calculated V follows the trend of the measured data accurately over the three geographical areas (for a detailed discussion see Wang et al. [30]). The Wood [31] equation outlines the layer of non-rigid sediment (consisting of mineral grains suspended in fluid), is also plotted in Figure 4. Only a few points in the shallow area fall below the Wood equation line, these may be caused by measurement errors. The Wood equation defines the lower boundary of $\mathrm{V}$, and the measured velocities appear above this lower boundary [31].

In addition to the factors discussed above, there are many other factors influencing sound velocity. Some scholars have studied the effects of temperature, pressure and salinity on sound velocity [32,33]. 
When a sediment sample is removed from the surface of the seafloor to the laboratory, the salinity of the water within the pore spaces remains the same, and the only changes (disregarding possible disturbances to sediment structure) are in temperature and pressure [33]. The effect of temperature on sound velocity had been studied by Carbó and Molero [32], and they found a velocity increase of $3.25 \mathrm{~m} / \mathrm{s}$ at a frequency of $1 \mathrm{MHz}$ when the temperature increases $1{ }^{\circ} \mathrm{C}$ on average. When the frequency decreases, the acoustic attenuation decreases, and the sound velocity decreases the rate of change. The frequency we used is only $100 \mathrm{kHz}$, is much smaller than $1 \mathrm{MHz}$, and the velocity increases at a rate smaller than $3.25 \mathrm{~m} / \mathrm{s}$. Moreover, the method we used can reduce the influence of temperature on sound velocity. We removed the polyethylene core liner with the cylindrical sample it contained and directly measured the sound velocity of the polyethylene core liner contents as soon as the core liner was removed from the gravity corer barrel. In this method, the temperature of sediment will not change much in a short time, thus, the value of sediment sound velocity changes little. Wang et al. [34] had researched the relation between the acoustic characters of sea bottom sediment and seawater depth, they found that when the water depth less than $1000 \mathrm{~m}$, the influence of depth on sound velocity can be ignored. In fact, changes in temperature and pressure are inevitable for sampling measurement, thus, the development of in situ measurement techniques is important for the measurement of sound velocity in seafloor [35].

In summary, our samples from the different geographical areas, when compared with the samples of previous studies, indicate that the physical properties, sediment types, geographical areas, and sand-silt-clay ratios are important factors that influence $\mathrm{V}$. The extent of the influence should be explored in further experimental and theoretical studies, and use of more discriminating acoustic techniques, like in situ measurement to acquire direct data, is necessary.

\section{Conclusions}

Measured data from gravity-cored seafloor samples in different geographical areas of the southern South China Sea were compared with empirical equations established by other researchers, and the significant differences were investigated. We conclude the following:

(1) Previously established equations relating the physical properties of seafloor sediment to their acoustic properties were not entirely accurate in the study area.

(2) We developed new empirical equations describing the relationships of the physical and acoustic properties of the samples, corresponding to the different geographical areas in our study area. Comparing the results of the new equations and the previous ones and analyzing the factors influencing the discrepancies between the results indicates that the physical properties, sediment types, geographical areas, and sand-silt-clay ratios are important factors affecting sound velocity in sediment.

(3) Future work in this field should include experimental and theoretical exploration of the influence of various potential impacting factors, and use of more discriminating acoustic techniques (such as in situ measurement). 


\section{Acknowledgments}

We thank Xinke Yu and the crew of the expedition ship R/V Kexueyihao for their assistance. This study is funded by the National Special Research Fund of China for Non-Profit Marine Sector (No.200905025).

\section{Author Contributions}

Zhengyu Hou analyzed the data and wrote this paper. Jingqiang Wang took the measurements. Wenjing Chen processed data used in this paper. Changsheng Guo, Yongtao Fu, and Tiegang Li helped in preparation and revision of the manuscript.

\section{Conflicts of Interest}

The authors declare no conflict of interest.

\section{References}

1. Gorgas, T.J.; Wilkens, R.H.; Fu, S.S.; Frazer, L.N.; Richardson, M.D.; Briggs, K.B.; Lee, H. In situ acoustic and laboratory ultrasonic sound speed and attenuation measured in heterogeneous soft seabed sediments: Eel River shelf, California. Mar. Geol. 2002, 182, 103-119.

2. Biot, M.A. Theory of propagation of elastic waves in a fluid-saturated porous solid. I. Low frequency range. J. Acoust. Soc. Am. 1956, 28, 168-178.

3. Biot, M.A. Theory of propagation of elastic waves in a fluid-saturated porous solid. II. Higher frequency range. J. Acoust. Soc. Am. 1956, 28, 179-191.

4. Stoll, R.D. Marine sediment acoustics. J. Acoust. Soc. Am. 1985, 77, 1789-1799.

5. Hamilton, E.L. Sound velocity and related properties of marine sediments, North Pacific. J. Geophys. Res. 1970, 75, 4423-4446.

6. Hamilton, E.L. Elastic properties of marine sediments. J. Geophys. Res. 1971, 76, 579-603.

7. Hamilton, E.L. Geoacoustic modeling of the sea floor. J. Acoust. Soc. Am. 1980, 68, 1313-1340.

8. Hamilton, E.L.; Bachman, R.T. Sound velocity and related properties of marine sediments. J. Acoust. Soc. Am. 1982, 72, 1891-1904.

9. Orsi, T.H.; Dunn, D.A. Sound velocity and related physical properties of fine grained abyssal sediments from the Brazil Basin (South Atlantic Ocean). J. Acoust. Soc. Am. 1990, 88, 1536-1542.

10. Brandes, H.G.; Silva, A.J.; Walter, D.J. Geo-acoustic characterization of calcareous seabed in the Florida Keys. Mar. Geol. 2002, 182, 77-102.

11. Lambert, D.N.; Kalcic, M.T.; Faas, R.W. Variability in the acoustic response of shallow-water marine sediments determined by normal-incident 30-kHz and 50-kHz sound. Mar. Geol. 2002, 182, 179-208.

12. Briggs, K.B.; Richardson, M.D. Small-scale fluctuations in acoustic and physical properties in surficial carbonate sediments and their relationship to bioturbation. Geo-Mar. Lett. 1997, 17, 306-315.

13. Richardson, M.D.; Briggs, K.B.; Bentley, S.J.; Walter, D.J.; Orsi, T.H. The effects of biological and hydrodynamic processes on physical and acoustic properties of sediments off the Eel River, California. Mar. Geol. 2002, 182, 121-139. 
14. Kim, G.Y.; Kim, D.C.; Yoo, D.G.; Shin, B.K. Physical and Geoacoustic properties of surface sediments off eastern Geoje Island, South Sea of Korea. Quat. Int. 2001, 230, 21-33.

15. Jackson, D.; Richardson, M. Geoacoustic properties. In High-Frequency Seafloor Acoustics; Springer Science \& Business Media: Berlin, Germany, 2007; pp. 123-170.

16. Lu, B.; Li, G.; Sun, D.; Huang, S.; Zhang, F. Acoustic-physical properties of seafloor sediments from near shore southeast China and their correlations. J. Tropi. Oceanogr. 2006, 25, 12-17. (In Chinese)

17. Lu, B.; Li, G.; Liu, Q.; Huang, S.; Zhang, F. Sea floor sediment and its acoustic-physical properties in the southeast open sea area of Hainan Island in China. Mar. Georesources Geotechnol. 2008, 26, 129-144.

18. Kan, G.; Liu, B.; Zhao, Y.; Li, G.; Pei, Y. Self-contained in situ sediment acoustic measurement system based on hydraulic driving penetration. High Technol. Lett. 2011, 17, 311-316.

19. Liu, B.; Han, T.; Kan, G.; Li, G. Correlations between the in situ acoustic properties and geotechnical parameters of sediments in the Yellow Sea, China. J. Asian Earth Sci. 2013, 77, 83-90.

20. Kim, D.C.; Sung, J.Y.; Park, S.C.; Lee, G.H.; Choi, J.H.; Kim, G.Y.; Kim, J.C. Physical and acoustic properties of shelf sediments, the South Sea of Korea. Mar. Geol. 2011, 179, 39-50.

21. Anderson, R.S. Statistical correlation of physical properties and sound velocity in sediments. In Physics of Sound in Marine Sediments; Hampton, L., Ed.; Plenum Press: New York, NY, USA, 1974; pp. 481-518.

22. Bachman, R.T. Acoustic and physical property relationships in marine sediment. J. Acoust. Soc. Am. 1985, 78, 616-621.

23. Han, D.; Nur, A.; Morgan, D. Effects of porosity and clay content on wave velocities in sandstones. Geophysics 1986, 51, 2093-2107.

24. Neto, A.A.; Teixeira Mendes, J.D.N.; de Souza, J.M.G.; Redusino, M., Jr; Leandro Bastos Pontes, R. Geotechnical influence on the acoustic properties of marine sediments of the Santos Basin, Brazil. Mar. Georesources Geotechnol. 2013, 31, 125-136.

25. Horn, D.R.; Horn, B.M.; Delach, M.N. Correlation between acoustical and other physical properties of deep-sea cores. J. Geophys. Res. 1968, 73, 1939-1957.

26. Kumar, T.P. A Study on the Geoacoustics Properties of the Marine Sediments. PhD Thesis, Cochin University Science \& Technology, Cochin, India, December 1999.

27. Chen, J.; Yan, P.; Wang, Y.L.; Jin, D.; Lin, Q. Choice of parameters for Biot-Stoll model-based inversion of sound velocity of seafloor sediments in the southern South China Sea. J. Trop. Oceanogr. 2012, 31, 50-54. (In Chinese)

28. Buckingham, M.J. Theory of acoustic attenuation, dispersion, and pulse propagation in unconsolidated granular materials including marine sediments. J. Acoust. Soc. Am. 1997, 102, 2579-2596.

29. Buckingham, M.J. Theory of compressional and shear waves in fluid like marine sediments. J. Acoust. Soc. Am. 1998, 103, 288-299.

30. Wang, J.; Guo, C.; Hou, Z.; Fu, Y.; Yan. J. Distributions and vertical variation patterns of sound speed of surface sediments in South China Sea. J. Asian Earth Sci. 2014, 89, 46-53.

31. Wood, A.B. A textbook of Sound; Bell and Sons LTD.: London, UK, 1941; p. 578. 
32. Carbó, R.; Molero, A.C. The effect of temperature on sound wave absorption in a sediment layer. J. Acoust. Soc. Am. 2000, 108, 1545-1547.

33. Hamilton, E. L. Prediction of in-situ acoustic and elastic properties of marine sediments. Geophys. 2012, 36, 266.

34. Wang, Q.; Liu, C.; Wu, Y.; Zhang, L.; Li, H. Relation between the acoustic characters of sea bottom sediment and the seawater depth. Appl. Acoust. 2008, 27, 217-221. (In Chinese)

35. Hou, Z.Y.; Guo, C.S.; Wang J.Q.; Li, H.Y.; Li, T.G. Tests of new in-situ seabed acoustic measurement system in Qingdao. Chin. J. Oceanol. Slimnol. 2014, 32, 1172-1178.

(C) 2015 by the authors; licensee MDPI, Basel, Switzerland. This article is an open access article distributed under the terms and conditions of the Creative Commons Attribution license (http://creativecommons.org/licenses/by/4.0/). 